LETTER TO JMG

\title{
Impact of homozygosity for an amyloidogenic transthyretin mutation on phenotype and long term outcome
}

\author{
G Holmgren, U Hellman, H-E Lundgren, O Sandgren, O B Suhr

Although amyloidogenic transthyretin (ATTR) mutations are common in several populations, such as black Americans, the small number of diagnosed patients homozygous for TTR amyloid and the short follow up in most studies has until now prevented an analysis of their phenotype. In Sweden, nine homozygous patients from eight families carrying the ATTR mutation Val30Met, which gives rise to fatal neuropathic amyloidosis (FAP), have been identified and have now been followed for up to 15 years. This has enabled an analysis of the phenotype of homozygous patients. Genetic testing and detection of amyloid deposits in the vitreous body or in intestinal or skin biopsies confirmed the diagnosis in all patients. The patients' symptoms were obtained from medical records. For comparison, we used a group of 35 heterozygous non-transplanted patients with FAP (18 men and 17 women), who had been evaluated at the Department of Medicine, Umea University Hospital before their deaths. Vitreous amyloidosis was the most prevalent symptom in the homozygous group, and in two patients it was the only manifestation of the disease during their lifetime. The age at onset was not different from that of heterozygous patients, and their survival tended not to be shorter but actually longer than for heterozygotes. Homozygosity for the mutation associated with FAP, ATTR Val30Met, does not implicate a more severe phenotype for Swedish patients. The most common symptom was vitreous opacity, which may be the only manifestation of the disease. These findings point to the possibilities of different pathways for amyloid formation, or the presence of hitherto unknown genes operating in amyloid formation.

$\mathrm{H}$ ereditary transthyretin (TTR) amyloidosis is generally regarded as a rare disease. However, amyloidogenic transthyretin (ATTR) mutations appear to be more common in the population than previously suspected. In black Americans, nearly 4\% carries the ATTR Vall22Ile mutation, associated with a late onset cardiomyopathy that is frequently overlooked and only diagnosed at postmortem examination. ${ }^{1}$ Nearly 90 different ATTR mutations are reported in the literature. ${ }^{2}$ They are inherited as an autosomal dominant trait with variable penetrance. Among the more common mutations is that causing familial amyloidotic polyneuropathy (FAP), a neuropathic systemic amyloidosis due to the ATTR Val30Met mutation. ${ }^{3}$ It is endemic in areas of Japan, Sweden, Portugal, and Brazil. ${ }^{4-7}$ In Sweden, the endemic areas are the counties of Västerbotten and Norrbotten in the northern part of the country. ${ }^{4}$ The mean age of onset for Swedish patients is 56 years, whereas in Japan and Portugal, the onset is around the age of
36 years. ${ }^{458}$ The disease gives rise to a fatal, often painful, sensorimotor somatic and autonomic polyneuropathy. Gastrointestinal disturbances is another symptom of the disease, as is impaired vision due to vitreous amyloid deposits. ${ }^{45-10}$ Heart complications are common, predominantly caused by conduction disturbances that often necessitate insertion of a pacemaker. ${ }^{11}{ }^{12}$ Patients in the latter stages of the disease are severely incapacitated, bedridden, or confined to a wheelchair, and often have urinary and faecal incontinence. The survival is variable but median survival is reportedly from 10 to 13 years after onset of the disease. ${ }^{413}$ Death is often a result of pronounced malnutrition and infections. ${ }^{9}{ }^{13}$

As TTR is predominantly synthesised by the liver, a liver transplant should replace the variant with the wild type TTR and thus halt amyloid formation. The first transplantation was carried out on one of our patients in 1990, and the progress of the disease was halted. ${ }^{14}$ Even though some unexpected complications have become apparent, the procedure is the only available treatment and is today carried out worldwide. ${ }^{15}$

The first Swedish patient with FAP was published in $1968,{ }^{10}$ and more than 600 patients with clinical manifestations of FAP have been diagnosed in northern Sweden since then. In one population study in this area, sera from 1276 healthy people aged 24-64 years were examined for the ATTR Val30Met mutation, and it was detected in 19 people, with 18 being heterozygous and 1 homozygous. ${ }^{16}$ The mean ATTR Val30Met carrier frequency was $1.5 \%$, ranging from 0.0 to $8.3 \%$ in 23 subpopulations. High frequency of the trait did not correlate with large numbers of patients; the largest concentration of symptomatic patients was in the Skelleftea area, where the frequency of the trait is $2.6 \%$, yet the onset and progress of the disease in that area, compared with Lycksele with a carrier frequency of close to $10 \%$, was earlier and more rapid. The estimated number of ATTR Val30Met carriers in Västerbotten and Norrbotten, which have close to 500000 inhabitants, is approximately 7500 . With only about 250 currently living patients with FAP, only $5-10 \%$ of the gene carriers appears to develop the disease. ${ }^{16}$ The high frequency of the trait and the finding of a asymptomatic homozygous carrier made it clear that a substantial number of homozygous carriers must be present, and the first homozygous patient and his homozygous asymptomatic sister were diagnosed in $1988 .{ }^{17}$

TTR is normally present as a tetramer. Tetramers of the amyloidogenic variants of TTR are unstable compared with wild type TTR, and it has been suggested that monomers assemble into amyloid after conformational changes. ${ }^{18}{ }^{19}$ In the plasma of heterozygous patients, TTR consists of different Abbreviations: ATTR, amyloidogenic transthyretin; FAP, fatal
neuropathic amyloidosis; TTR, transthyretin 
combinations of mutated and wild type TTR. The combination that is the most unstable, and therefore more amyloidogenic, has not been determined; however, amyloid from the corpus vitrium of affected patients contains approximately $80 \%$ variant $\mathrm{TTR}^{20}$ whereas amyloid from the heart and peripheral nerves contains $50-60 \%$, thus a substantial amount of wild type TTR is incorporated in the amyloid. ${ }^{21}{ }^{22}$ Furthermore, high concentrations of wild type TTR are found in the amyloid deposits in the heart from liver transplanted patients who died from increased cardiomyopathy after the procedure. ${ }^{22}$ Thus wild type TTR is amyloidogenic, as hasbeen shown for systemic senile amyloidosis. ${ }^{23}$

No systematic long term follow up of homozygous patients has been reported, so it has not been clarified if the TTR tetramer consisting of only ATTR Val30Met leads to a more aggressive disease than that originating from TTR consisting of a mixture of wild and mutant TTR.

The aim of the present investigation was to present the long term outcome of our patients who were homozygous for ATTR Val30Met with regard to survival and progression of symptoms, and to compare their outcome with that of heterozygous patients.

\section{PATIENTS AND METHODS}

\section{Patients}

The clinical data of the patients were obtained from medical records and interviews with the patients and their relatives. Testing for the ATTR Val30Met mutation and examination of surgical samples of corpus vitrium or intestinal or skin biopsies for amyloid deposits ascertained the diagnosis in all patients. The homozygous group consisted of nine Swedish patients (five men, four women; table 1). The heterozygous group consisted of all 35 deceased non-transplanted patients (18 men, 17 women), who had been evaluated at the Department of Medicine, Umeå University Hospital, and in whom genetic testing had been performed. Their onset of disease was between 1968 and 1993. Because better treatmetn for infections and nutritional depletion has been implemented during more recent years, a bias towards a shorter survival for this retrospective cohort compared with survival nowadays cannot be excluded.

\section{Genetic testing}

Over time, different methods have been used to detect the ATTR Val30Met mutation. The first four patients discovered to be homozygous for the mutation were analysed with Southern blotting. The remaining five patients were diagnosed by PCR based methods as previously described. ${ }^{24} 25$

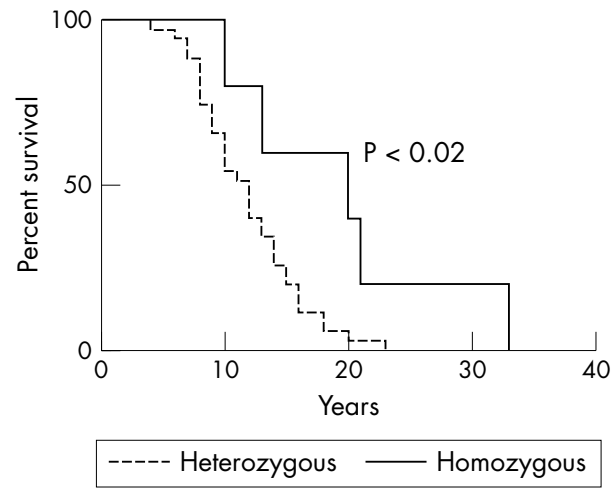

Figure 1 Kaplan-Meier plot of survival after onset of disease for eight homozygous (seven deceased and one living) and 35 heterozygous (deceased) ATTR Val30Met patients.

\section{Statistics}

Non-parametric statistical and descriptive analyses were used. Comparisons between groups were done with the Mann-Whitney test. Kaplan-Meier plot was used to display survival and comparison between group survival was performed by log rank test (fig 1). A p value $<0.05$ was considered significant. Prism 4 for Macintosh (GraphPad Software Inc., San Diego, CA, USA) was used for statistical analysis.

\section{RESULTS}

The clinical data of the nine Swedish homozygous ATTR Val30Met carriers belonging to eight families are presented in table 1. Two of the nine patients, including one liver transplanted patient, have not been previously presented. They were all detected during the routine DNA diagnostic test for FAP. ${ }^{1724}{ }^{26}$ The father of one patient (patient 9) had died from the disease; otherwise, the patients were sporadic without known symptomatic carriers in previous generations. However, several heterozygous siblings had developed the disease, as had a few children of some of the presented patients. Of the pair of homozygous siblings, only one developed systemic disease (patient 2 , table 1 ).

All homozygous carriers developed vitreous amyloidosis, which was the first symptom of the disease in four patients. In two patients (patients 1 and 5), vitreous opacities were the only manifestation of FAP. One patient underwent liver transplant (patient 9), and he developed vitreous opacities 3 years after transplantation at the age of 47 years. However, his outcome after transplantation was not different from that

Table 1 Clinical data of the nine homozygous ATTR Val30Met mutation patients

\begin{tabular}{|c|c|c|c|c|c|c|c|c|c|}
\hline \multirow{2}{*}{$\begin{array}{l}\text { Patient } \\
\text { no. }\end{array}$} & \multirow[b]{2}{*}{ Sex } & \multirow{2}{*}{$\begin{array}{l}\text { Age } \\
\text { at onset }\end{array}$} & \multirow{2}{*}{$\begin{array}{l}\text { Age } \\
\text { at death }\end{array}$} & \multirow{2}{*}{$\begin{array}{l}\text { Symptoms } \\
\text { at onset }\end{array}$} & \multicolumn{4}{|c|}{$\begin{array}{l}\text { Additional } \\
\text { symptoms during the } \\
\text { course of the disease }\end{array}$} & \multirow{2}{*}{$\begin{array}{l}\text { Affected } \\
\text { family members }\end{array}$} \\
\hline & & & & & PN & GI & H & vo & \\
\hline 1 & $\mathrm{~F}$ & 64 & 78 & VO & 0 & 0 & 0 & + & Brother (no. 2) \\
\hline 2 & $M$ & 52 & 65 & PN & + & + & 0 & + & Sister (no. 1) \\
\hline 3 & $\mathrm{~F}$ & 58 & 78 & PN & + & + & 0 & + & Brother, sister \\
\hline 4 & $\mathrm{~F}$ & 55 & 86 & VO & + & + & 0 & + & Daughter \\
\hline 5 & $M$ & 56 & 73 & VO & 0 & 0 & 0 & + & Brother \\
\hline 6 & $M$ & 55 & 76 & PN & + & 0 & 0 & + & Daughter \\
\hline 7 & $M$ & 54 & 64 & PN & + & 0 & 0 & + & None \\
\hline 8 & $\mathrm{~F}$ & 79 & Alive & VO & + & 0 & 0 & + & None \\
\hline 9 & $M$ & 39 & Alive & $\mathrm{PN}$ & + & 0 & 0 & + & Father, sister \\
\hline
\end{tabular}


of the heterozygous patients, and the progression of his neuropathy has come to a halt.

One homozygous female carrier was asymptomatic at the time of diagnosis (patient 1). She died 16 years later at the age of 78 years, with no other symptoms of amyloidosis except for vitreous deposits. Patient 5 had a similar pattern, surviving for 17 years after onset of eye symptoms. Both patients were successfully operated for amyloid opacities by vitrectomy. None of the studied patients have developed heart complications in the form of conduction disturbances nor has any received a pacemaker. The onset of disease was between 39 and 79 years of age (median 55). Seven of the patients died after a median duration of their disease of 17 years (range 10-31). After excluding the patients who never developed symptoms of systemic amyloidosis (patients 1 and 5), a similar median survival of 17 years was found for the remaining five deceased patients.

The median age at onset for heterozygous FAP patients was 56 years (range 29-74), and median survival was 12 years (range 4-23). In comparing the age at onset of disease for homozygous and heterozygous patients, no differences were noted. However, the survival was longer for homozygous patients $(p<0.02 ; 95 \%$ confidence interval (CI) 0.26 to 1.15$)$, and remained significant after exclusion of patients with eye symptoms only ( $\mathrm{p}<0.05 ; 95 \%$ CI 0.21 to 0.99 ).

Vitreous opacities were not diagnosed in any of the heterozygous patients; however, their disease has not been followed as carefully as the homozygous, so we cannot exclude that some had developed vitreous opacities at the end stage of their disease.

\section{DISCUSSION}

Including the present study of 9 individuals, 19 homozygous ATTR Val30Met gene carriers have been reported in the literature. The clinical picture and age at onset of the Spanish patients were similar to that reported for Spanish-Majorcan patients, even though their sensorimotor syndrome was described as more aggressive. ${ }^{27}$ The Turkish patients were interesting because only homozygous members of the family appeared to developed symptoms. ${ }^{28}$ However, if homozygosity had been the basis for clinical expression of the trait in Swedish families, we would have expected that their heterozygous siblings should have remained unaffected, and that a homozygous sibling should have developed systematic disease. However, our data do not support this hypothesis. Considering the prevalence of the trait of $1.5 \%$, the expected number of homozygous carriers is approximately 110 in the area studied. The penetrance is estimated to be between $5-10 \%$, thus the nine individuals identified is close to the expected number of symptomatic patients, and indicates that the penetrance is not markedly different than that noted for heterozygous individuals. ${ }^{16}$

One of the homozygous Japanese patients reported by Yosinaga et al had unusually heavy depositions of amyloid in leptomeninges and subarachnoid vessels; ${ }^{29}$ however, the patient's age at onset was 58 years, which is comparatively late for a Japanese patient. He died 9 years later from the disease, indicating a survival that is not different from that usually reported for Japanese patients. The same group of researchers has previously reported on an asymptomatic ATTR Val30Met carrier and also late onset homozygous patients, so they concluded that Japanese homozygous patients appear to present a clinical picture not markedly different from that of heterozygous FAP patients. ${ }^{29-32}$

A few patients homozygous for non-ATTRVal30Met have been reported. From those studies, it has not been possible to determine if homozygosity for non-ATTR Val30Met variants is more amyloidogenic than heterozygosity, even though early onset cardiomyopathy has been reported for a homozygous ATTR Phe62Leu patient. ${ }^{33-35}$ Considering that the prevalence of the genetic trait for ATTR Vall22Ile in black Americans is close to $4 \%,{ }^{1}$ relatively few homozygous patients have been reported, and their disease appears not to have a earlier onset than in heterozygotes.

From the available data, the presence of TTR tetramers consisting only of mutant ATTR Val30Met neither accelerates the disease progression nor makes the phenotype more malignant. Age at onset and length of survival for heterozygous patients are similar to that reported in initial studies of Swedish FAP patients. ${ }^{413}$ Age of onset for homozygous patients is not different from that of heterozygotes and their survival is similar or actually longer than that observed for heterozygotes. This is different from that observed for Huntington's disease where homozygosity for the CAG mutation is associated with a more severe clinical course, even though the age at onset is similar in heterozygotes. ${ }^{36}$ It should be observed, however, that the advanced age of onset for many Swedish FAP patients implies that many patients did not succumb to their amyloid disease, but to other age related diseases. In the present study, it was not possible to obtain valid information on the cause of death in all patients. In addition, vitreous opacity was a common initial symptom of the disease in homozygotes and may not indicate the presence of systemic amyloid disease. The correlation between eye deposits and systemic deposits of amyloid has not been studied.

Vitreous opacity was also a common finding in Japanese and Spanish patients. ${ }^{27}{ }^{30}$ Two of our homozygous patients died at a relatively old age, reportedly without other manifestations of the disease except for vitreous amyloid deposits. According to an earlier study, $15-20 \%$ of the Swedish FAP population including homozygous patients developed vitreous opacities. ${ }^{37}{ }^{38}$ All homozygous Swedish patients have developed vitreous opacities, and even though we can not exclude that some of the heterozygous patients in the control group developed this complication, it is definitively more common in homozygous. The special environment in the eye, with fewer proteins in the vitreous body than in, for example, the extracellular fluid, may facilitate amyloid formation from TTR tetramers consisting of ATTR Val30Met only. In heterozygotes, the relatively high content of variant TTR in the vitreous amyloid deposits compared with that observed in peripheral nerves and heart suggests that different fibril formation pathways may be operating. An alternative explanation may be an influence of as yet unknown genes operating in TTR amyloid diseases, which have an impact on the phenotype of the disease.

In summary, homozygous Swedish patients do not display a more aggressive or a more rapidly developing FAP disease. The clinical presentation more frequently involves vitreous opacities, which may remain as the only manifestation of the disease. Different pathways for systemic and eye amyloid formation may exist.

\section{ACKNOWLEDGEMENTS}

This work was supported by grants from the patient organisation FAMY Västerbotten, FAMY/AMYL Norrbotten ( $\mathrm{O}$ B Suhr), the National Medical Research Organisation, Vetenskapsrådet (project numbers 9745 (G Holmgren) and 13045 (O B Suhr)), and Umeå University.

\section{Authors' affiliations}

G Holmgren, U Hellman, Department of Clinical Genetics/Medical Bioscience, Umeå University Hospital, Umeå, Sweden

H-E Lundgren, O B Suhr, Department of Public Health and Clinical Medicine, Umeå University Hospital, Umeå, Sweden

O Sandgren, Department of Clinical Sciences/Ophthalmology, Umeå University Hospital, Umeå, Sweden 
Competing interests: none declared

Ethics: The study was conducted according to the principles of the Helsinki Declaration.

Correspondence to: $\operatorname{Dr} O$ B Suhr, Department of Medicine, Umeå University Hospital, SE 90185 Umeå, Sweden; ole.suhr@medicin.umu.se Received 7 April 2005

Revised form received 16 May 2005

Accepted for publication 18 May 2005

Published Online First 1 June 2005

\section{REFERENCES}

1 Jacobson DR, Pastore RD, Yaghoubian R, Kane I, Gallo G, Buck FS Buxbaum JN. Variant-sequence transthyretin (isoleucine 122) in late-onset cardiac amyloidosis in black Americans. N Engl J Med 1997;336:466-73.

2 Connors LH, Lim A, Prokaeva T, Roskens VA, Costello CE. Tabulation of human transthyretin (TTR) variants, 2003. Amyloid 2003;10:160-84.

3 Tawara S, Nakazato M, Kangawa K, Matsuo H, Araki S. Identification of amyloid prealbumin variant in familial amyloidotic polyneuropathy (Japanese type). Biochem Biophys Res Commun 1983;116:880-8.

4 Andersson R. Familial amyloidosis with polyneuropathy. A clinical study based on patients living in northern Sweden. Acta Med Scand Suppl 1976;590: 1-64.

5 Araki S. Type I familial amyloidotic polyneuropathy (Japanese type). Brain Dev 1984;6:128-33.

6 Andrade C. A peculiar form of peripheral neuropathy. Familiar atypical generalized amyloidosis with special involvement of the peripheral nerves. Brain, 1952:75, 408-27.

7 Bittencourt PL, Couto CA, Farias AQ, Marchiori P, Bosco Massarollo PC, Mies S. Results of liver transplantation for familial amyloid polyneuropathy type I in Brazil. Liver Transpl 2002;8:34-9.

8 Coutinho $P$, da Silva AM, Lima JK, Barbosa AR. Forty years of experience with type I amyloid neuropathy. Review of 483 cases. In: Glenner GG, e Costa PP, de Freitas AF, eds. Amyloid and amyloidosis. Amsterdam, Oxford, Princeton, Excerpta Medica, 1979:88-98.

9 Steen L, Ek B. Familial amyloidosis with polyneuropathy. A long-term follow up of 21 patients with special reference to gastrointestinal symptoms. Acta Med Scand 1983;214:387-97.

10 Andersson R, Kassman T. Vitreous opacities in primary familial amyloidosis. Acta Ophthalmol Copenh 1968;46:441-7

11 Eriksson P, Karp K, Bjerle P, Olofsson BO. Disturbances of cardiac rhythm and conduction in familial amyloidosis with polyneuropathy. Br Heart $J$ 1984;51:658-62.

12 de Freitas AF. The heart in Portuguese amyloidosis. Postgrad Med J 1986:62:601-5.

13 Suhr O, Danielsson A, Holmgren G, Steen L. Malnutrition and gastrointestinal dysfunction as prognostic factors for survival in familial amyloidotic polyneuropathy. J Intern Med 1994;235:479-85.

14 Holmgren G, Ericzon BG, Groth CG, Steen L, Suhr O, Andersen O Wallin BG, Seymour A, Richardson S, Hawkins PN, Pepys MB. Clinical improvement and amyloid regression after liver transplantation in hereditary transthyretin amyloidosis. Lancet 1993;341:1113-16.

15 Suhr OB, Herlenius G, Friman S, Ericzon BG. Liver transplantation for hereditary transthyretin amyloidosis. Liver Transpl 2000;6:263-76.

16 Holmgren G, Costa PM, Andersson C, Asplund K, Steen L, Beckman L, Nylander PO, Teixeira A, Saraiva MJ, Costa PP. Geographical distribution of TTR met30 carriers in northern Sweden: discrepancy between carrier frequency and prevalence rate. J Med Genet 1994;31:351-4.

17 Holmgren G, Haettner E, Nordenson I, Sandgren O, Steen L, Lundgren E. Homozygosity for the transthyretin-met30-gene in two Swedish sibs with familial amyloidotic polyneuropathy. Clin Genet 1988;34:333-8.

18 Lai Z, Colon W, Kelly JW. The acid-mediated denaturation pathway of transthyretin yields a conformational intermediate that can self-assemble into amyloid. Biochemistry 1996;35:6470-82.

19 Colon W, Lai Z, McCutchen SL, Miroy GJ, Strang C, Kelly JW. FAP mutations destabilize transthyretin facilitating conformational changes required for amyloid formation. Ciba Found Symp 1996;199:228-38.
20 Ando Y, Ando E, Ohlsson PI, Olofsson A, Sandgren O, Suhr O, Terazaki H, Obayashi K, Lundgren E, Ando M, Negi A. Analysis of transthyretin amyloid fibrils from vitreous samples in familial amyloidotic polyneuropathy (Val30Met). Amyloid 1999;6:119-23.

21 Yazaki M, Liepnieks JJ, Kincaid JC, Benson MD. Contribution of wild-type transthyretin to hereditary peripheral nerve amyloid. Muscle Nerve 2003;28:438-42

22 Yazaki M, Tokuda T, Nakamura A, Higashikata T, Koyama J, Higuchi K, Harihara Y, Baba S, Kametani F, Ikeda S. Cardiac amyloid in patients with familial amyloid polyneuropathy consists of abundant wild-type transthyretin. Biochem Biophys Res Commun 2000;274:702-6

23 Westermark P, Sletten K, Johansson B, Cornwell GGd. Fibril in senile systemic amyloidosis is derived from normal transthyretin. Proc Natl Acad Sci USA 1990;87:2843-5.

24 Holmgren G, Holmberg E, Lindstrom A, Lindstrom E, Nordenson I, Sandgren O, Steen L, Svensson B, Lundgren E, von Gabain A. Diagnosis of familial amyloidotic polyneuropathy in Sweden by RFLP analysis. Clin Genet 1988;33:176-80.

25 Holmgren G, Bergstrom S, Drugge U, Lundgren E, Nording-Sikstrom C, Sandgren O, Steen L. Homozygosity for the transthyretin-Met30-gene in seven individuals with familial amyloidosis with polyneuropathy detected by restriction enzyme analysis of amplified genomic DNA sequences. Clin Genet 1992;41:39-41.

26 Holmgren G, Lundgren E, Kangawa K, Kurihara T, Matsukura S, Matsuo H, Nakazato M, Steen L. Diagnostic radioimmunoassay and DNA-analysis in Swedish and Japanese patients with familial amyloidotic polyneuropathy. Homozygosity for the TTR met30 gene. Acta Neurol Scand 1993;87:124-7.

27 Munar-Ques M, Lopez Dominguez JM, Viader-Farre C, Moreira P, Saraiva MJ. Two Spanish sibs with familial amyloidotic polyneuropathy homozygous for the V30M-TTR gene. Amyloid 2001;8:121-3.

28 Skare J, Yazici H, Erken E, Dede H, Cohen A, Milunsky A, Skinner M. Homozygosity for the met30 transthyretin gene in a Turkish kindred with familial amyloidotic polyneuropathy. Hum Genet 1990;86:89-90.

29 Yoshinaga T, Takei Y, Katayanagi K, Ikeda S. Postmortem findings in a familial amyloid polyneuropathy patient with homozygosity of the mutant Val30Met transthyretin gene. Amyloid 2004:11:56-60.

30 Yoshinaga T, Nakazato M, Ikeda S, Ohnishi A. Homozygosity for the transthyretin-Met30 gene in three Japanese siblings with type I familial amyloidotic polyneuropathy. Neurology 1992;42:2045-7.

31 Ikeda S, Nakano T, Yanagisawa N, Nakazato M, Tsukagoshi $H$. Asymptomatic homozygous gene carrier in a family with type I familial amyloid polyneuropathy. Eur Neurol 1992;32:308-13.

32 Yoshioka A, Yamaya Y, Saiki S, Hirose G, Shimazaki K, Nakamura M, Ando $Y$. A case of familial amyloid polyneuropathy homozygous for the transthyretin Val30Met gene with motor-dominant sensorimotor polyneuropathy and unusual sural nerve pathological findings. Arch Neurol 2001;58:1914-18.

33 Ferlini A, Salvi F, Uncini A, el-Chami J, Winter $P$, Altland $K$, Repetto $M$, Littardi M, Campoleoni A, Vezzoni P, Patrosso MC. Homozygosity and heterozygosity for the transthyretin Leu64 mutation: clinical, biochemical and molecular findings. Clin Genet 1996;49:10-14.

34 Jacobson DR, Gorevic PD, Buxbaum JN. A homozygous transthyretin variant associated with senile systemic amyloidosis: evidence for a late-onset disease of genetic etiology. Am J Hum Genet 1990;47:127-36.

35 Nichols WC, Liepnieks JJ, Snyder EL, Benson MD. Senile cardiac amyloidosis associated with homozygosity for a transthyretin variant (ILE-122). J Lab Clin Med 1991;117:175-80.

36 Squitieri F, Gellera C, Cannella M, Mariotti C, Cislaghi G, Rubinsztein D, Almqvist EW, Turner D, Bachoud-Levi AC, Simpson SA, Delatycki M, Maglione V, Hayden MR, Donato SD. Homozygosity for CAG mutation in Huntington disease is associated with a more severe clinical course. Brain 2003; 126:946-55

37 Sandgren O, Drugge U, Holmgren G, Sousa A. Vitreous involvement in familial amyloidotic neuropathy: a genealogical and genetic study. Clin Genet 1991;40:452-60

38 Sandgren $\mathrm{O}$, Holmgren G, Lundgren E. Vitreous amyloidosis associated with homozygosity for the transthyretin methionine-30 gene. Arch Ophthalmol 1990;108:1584-6. 